\title{
Youth, Agriculture and Land Grabs in Malawi
}

\author{
Blessings Chinsinga and Michael Chasukwa
}

\begin{abstract}
Malawi has received international media attention as a potential model for a uniquely African green revolution following the success of its fertiliser subsidy programme. The role of young people has not featured at all in this success story, although more than half of the population is considered young. Meanwhile, the government's Green Belt Initiative is planning to give land to large-scale local and foreign investors for irrigated agriculture along Lake Malawi and major rivers to consolidate food security gains. The concern is that vast tracks of land are being appropriated from smallholder farmers whose land ownership averages only 0.5 hectare. This article explores how young people are engaging with these initiatives in terms of their roles and what they perceive as potential alternative livelihood strategies within the agri-food sector. It argues that young people are marginalised from these successes because of stalled land reforms and absence of a supportive policy environment.
\end{abstract}

\section{Introduction}

This article explores young people's engagement in the agri-food sector in Malawi against the backdrop of two key related developments, namely: the Farm Input Subsidy Programme (FISP) and the Green Belt Initiative (GBI). Young people are a critical constituency in Malawi since they form more than half of the total population, estimated at 13.1 million (NSO 2008), with potentially significant implications for future trajectories of growth and development.

Since the 2005/06 growing season, Malawi has implemented a FISP which has been held as a tremendous success (Dorward and Chirwa 2011). The success has been underlined by the country's ability to produce a food surplus after almost two decades of pervasive food insecurity and chronic food shortages. Malawi is now able to feed itself without taking recourse either to food aid or commercial food imports. As a result of this unprecedented success, Malawi features as a model in international policy dialogue for other countries on the African continent to emulate in order to kickstart their fledging agricultural sectors as engines of growth and sustainable poverty reduction (UNESCO 2009; AGRA 2009; Chinsinga 2010).
There is, however, intense debate about the sustainability of the success of the FISP in keeping Malawi both food secure and selfsufficient. This debate is mainly led by a group of donors sceptical about the efficiency and effectiveness of the FISP in the use of valuable inputs, aside from its affordability in the long term (Dorward and Chirwa 2011). Questions about the capacity of the government to properly target beneficiaries to limit the potential distortionary effects of subsidies, the impact of consecutive years of favourable climatic patterns on the success of the FISP and the opportunity cost of resources invested in the programme are among the many issues raised (Chirwa 2008; Holden and Tostensen 2011).

As a response to some of these questions, the government is implementing the GBI to secure the long-term food security and sufficiency gains through the development of small and largescale irrigation schemes and maximisation of rain-fed agriculture practices (Chingaipe $e t$ al. 2011). Under the GBI, the government has committed itself to offer local and international investors land amounting to about 1 million hectares for irrigated agriculture.

IDS Bulletin Volume 43 Number 6 November 2012 (c) 2012 The Authors. IDS Bulletin ( 2012 Institute of Development Studies Published by Blackwell Publishing Ltd, 9600 Garsington Road, Oxford OX4 2DQ, UK and 350 Main Street, Malden, MA 02148, USA 
However, a major concern is that the GBI is being promoted at a time of virtual impasse in land reforms intended to correct chronic imbalances in land tenure and ownership patterns that have left the vast majority of smallholder farmers virtually landless (Chingaipe et al. 2011). The average per capita land ownership in Malawi is estimated at 0.5 hectare. This is considered inadequate to the extent that the land at the disposal of the majority of smallholder farmers is described as 'simply providing a cushion or safety net that will provide them with a base while their primary incomes need to be generated elsewhere' (Smith 1998).

The central argument of this article is that young people are being marginalised in Malawi's green revolution success story because of stalled land reforms and the absence of a supportive policy infrastructure for their involvement in the agri-food sector. The land reform impasse, which is in the interest of the bureaucratic and political elite, disempowers young people as key actors in the sector. Since the transition to democracy in 1994, there have been no significant policy pronouncements on young people's role and involvement in the agri-food sector. While clearly prioritising the agricultural sector as the engine of growth and poverty reduction, the overarching development strategies such as the Poverty Alleviation Programme (PAP) (1995), the Malawi Poverty Reduction Strategy (MPRS) (2001) and the Malawi Growth and Development Strategy (MGDS) (2006) have been almost totally silent on the role and involvement of young people in the sector. The policy vacuum is exacerbated by the reluctance of the young experts in the sector to be deployed in the rural areas to provide technical and extension support services to farmers.

The article is based on fieldwork carried out in two districts in southern Malawi: Zomba and Mangochi. These districts were purposefully chosen for two reasons. According to their socioeconomic profiles, Zomba and Mangochi have a disproportionate share of young people in their demographic structures and highlight serious concerns with increasing pressure on arable land due to extensive estate farming. They are among the densely populated districts in Malawi. Mangochi and Zomba's population densities are estimated at 128 and 230 people per square kilometre, respectively, compared to the national average estimated at 139 people per square kilometre. The major crops cultivated in both districts are maize and tobacco, which are grown as food and cash crops respectively. Mangochi is bigger than Zomba in terms of total land area. While Zomba covers a total land area of 2,580 square kilometres, Mangochi's total land area is estimated at 6,273 square kilometres, translating to about 6.7 per cent of Malawi's total land area (NSO 2008).

The fieldwork was entirely qualitative using focus group discussions (FGD) and key informant interviews with young people and Ministry of Agriculture, Irrigation and Water Development (MoAI\&WD) officials. A qualitative approach because it provides a means of acquiring an indepth understanding of human behaviour through the opportunity to explore issues, understand phenomena and answer questions (Bryman 2001; Campbell 2002).

The following section examines the primacy of agriculture in Malawi and particularly the role of young people. It also examines briefly the FISP and the GBI to set the context for the rest of the discussion. The third section discusses the empirical realities of young people's engagement in the agri-food sector highlighting constraints and opportunities including implications for the future of the sector. The final section reflects on the missed opportunity to engage with young people in rural areas, because they were excluded from current development initiatives.

\section{The primacy of agriculture, and young people in Malawi}

Agriculture is the principal source of livelihood in Malawi. Up to 84 per cent of Malawians eke their living directly out of agriculture which contributes over 90 per cent to the country's export earnings, about 39 per cent of the country's GDP and accounts for 85 per cent of total employment (Chirwa 2004; Chinsinga 2008).

The country's agricultural sector has undergone little notable transformation. Rather than diminishing, the agricultural sector is becoming increasingly dominant in the country's overall economic portfolio (Chinsinga 2002; Chirwa et al. 2006). This increase is partly attributed to the devastating effects of structural adjustment programmes on the manufacturing sector. The contribution of the manufacturing sector to the country's GDP decreased from 16 to 11 per cent 
between 1994 and 2004 because of the total collapse or relocation of industries to neighbouring countries within the region. Agroprocessing constitutes 26 per cent of manufacturing, less than 3 per cent of GDP (Chinsinga 2008).

The overwhelming dominance of the agricultural sector in the country's overall economic portfolio highlights the critical issue of access to land. It is a significant determinant of whether a household will be food secure, less vulnerable to risks and shocks, and earn a living above the poverty line. However, ownership of land and distribution is highly unequal in Malawi. An estimated 70 per cent of smallholders cultivate less than a hectare and devote 70 per cent of their land to maize, the main staple (Chirwa 2004; Chinsinga 2008). Between 1.8 and 2 million smallholder farmers cultivate on average 1 hectare or less, while 30,000 estates own or lease 10-500 hectares of land each ${ }^{1}$ (Kanyongolo 2005).

The land problem contributes to what Dorward and Chirwa (2011) refer to as the 'low maize productivity trap' in Malawi where farmers with small pieces of land continue to cultivate maize even when it is not efficient for them to do so. This is reinforced by high input prices and interyear maize price instability. The fear of low maize prices does not make it attractive for potential maize surplus producers to invest in maize production, while the fear of high maize prices forces maize deficit farmers to grow as much maize as they can on their small pieces of land even though they cannot afford highyielding seeds and fertiliser. The Farm Input Subsidy Programme is a potential means of breaking down the constraints that have locked Malawi into a low maize productivity trap, making high-quality farm inputs accessible to the majority of smallholders who would otherwise not have access to them.

The latest stalled land reforms are linked to the democratisation project of the 1990s which kicked off with a Presidential Commission of Inquiry on Land Reform in 1996, culminating in the development of a draft land policy endorsed by the Cabinet in July 2002 (Peters and Kambewa 2007). A Special Law Commission was empanelled in 2003, tasked to review existing land legislation and develop new legislation for effective land administration by consulting as widely as possible with relevant stakeholders. The enabling legislative framework for the land policy is yet to be promulgated into law although the Special Law Commission wound up its work more than seven years ago (Chinsinga 2011). The impasse in implementation is attributed mainly to the desire of the political and bureaucratic elite to protect and defend their own interests. Many acquired massive tracts of land under the auspices of previous land reforms which they are not prepared to give up even though much of it lies idle.

This is precisely the concern with the Green Belt Initiative: it does not target underutilised land owned by the political and bureaucratic elite but that owned by smallholder farmers (Chingaipe $e t$ al. 2011), the majority of whom are grappling with an acute shortage of land. The GBI is driven by government's realisation that a major investment challenge encountered by big farmers is the lack of large tracts of land viable for commercial farming to realise the highest possible economies of scale. Thus through the GBI, the government has committed itself to facilitate acquisition of almost 1 million hectares of land, mainly from smallholder farmers. A distinctive feature of the land grabs in Malawi is that they are supply-driven. The government is courting potential local and international investors by offering them land to be acquired from smallholder farmers for large-scale irrigation schemes.

According to the GBI concept paper, it is inspired by the painful memories of the severe drought beginning in early 2001 which triggered three consecutive years of hunger. By 2005, 5 million people were affected by famine; while large quantities of water flowed out of the country to the ocean. The GBI is seen as a mechanism to protect gains in food security, reduce vulnerability to drought, and diversify crop production by irrigating a million hectares of land lying within $20 \mathrm{~km}$ of the country's three lakes and 13 perennial rivers (GoM 2009). The GBI is, however, not without critics. They argue that the promises of job creation and foreign exchange earnings through foreign investment should not substitute the need for policies that would grow domestic investment. As an MoAI\&WD official in Zomba District put it: 'If we allow foreigners to grab land in the Belt, we will lose out on the market because they will be 
Figure 1 Malawi population pyramid for 2010

Male

Female

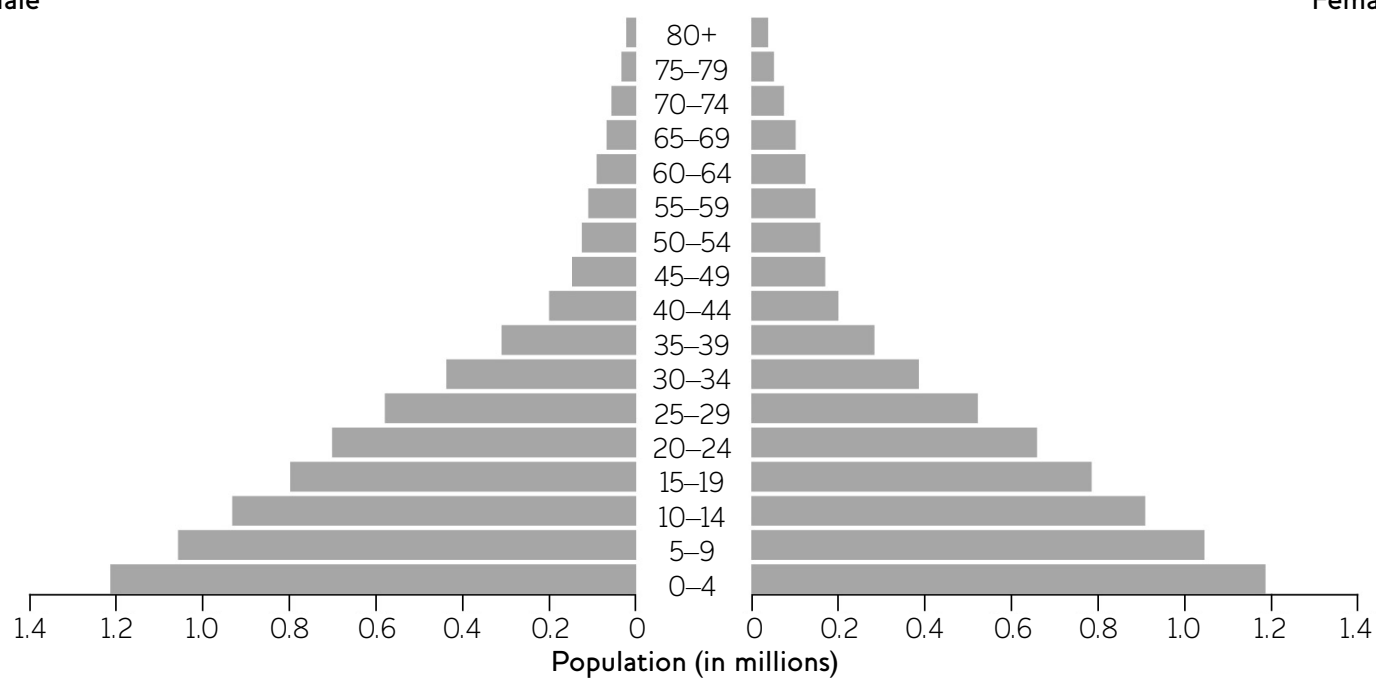

Source Redrawn from www.nationmaster.com/country/mi-mal (accessed 9 March 2012).

producing what they need for their countries instead of us producing what they would need and selling it to them.'

Malawi is dominated by a youthful population as Figure 1 clearly illustrates. This has significant implications for its future development in various spheres, not least the agri-food sector.

However, the question of who exactly qualifies as 'youth' is not straightforward either internationally or locally. The National Youth Policy defines youth as all young people, female and male, from the age of 14 to 25 years, while acknowledging that youth is not a chronological sequence but also a term used to describe roles ascribed to the young (GoM 2008). The implication is that the term 'youth' is employed flexibly, so that young people less than 14 and over 25 years can be accommodated depending on their socioeconomic circumstances.

Several important programmes targeting young people do not use the definition stipulated in the National Youth Policy. The Malawi Rural Development Fund (MARDEF) and the Youth Enterprise Development Fund (YEDEF) designate youth as males and females aged between 18 and 35. In proposals to revise the National Youth Policy, youth will include all males and females aged between 14 and 30. A further layer of complexity comes about when young people are considered in the agricultural context. According to MoAI\&WD officials '[youth] are those that have not yet married or are living with a guardian and are not able to support themselves'. This suggests that in the agricultural sector, age is not necessarily the factor used to distinguish between youths and adults. Rather, youth are essentially those who are not married and cannot sustain themselves economically.

Competing perspectives are also manifested at the international level with definitions of youth varying tremendously. For instance, the United Nations defines youth as all individuals aged between 15 and 24, while the World Bank expands the definition to include all young people aged between 12 and 24. Overall, however, policy discussions have been based on the premise that the youth are in transition from childhood to adulthood. As such, young people have specific characteristics that make them a distinct demographic and social category (Bennel 2007).

Munthali (2010) views young people as a doubleedged sword. On the one hand they present an unprecedented demographic dividend of human resources, while on the other, the demographic bonus could easily turn into a catastrophe if young people are not equipped with the right skills for the job market and more importantly self-employment skills. In the case of Malawi, this makes the agri-food sector a priority. The 
formal sector is very small, estimated at 500,000 jobs only and projected to shrink further due to the devastating economic crisis affecting global and national economies since 2007.

\section{Youth and agriculture: empirical realities} 3.1 Young people's vision of 'the good life'

It is striking that young people in our study do not define their vision of 'the good life' with reference to their involvement in the agriculture sector. Conceptions mostly revolved around 'owning a decent iron sheet roofed house, ready availability of food and fashionable clothes for our families, sending children to a good boarding school and at least having a mountain bike and a television screen'. ${ }^{2}$ Young people feel strongly that their vision of 'the good life' cannot be achieved by spending their time, and investing their energies in, the agricultural sector. They argue that life in farming is not only demanding but also a huge gamble in view of the challenges facing the sector. Young men at Chitenjere Village, Malosa EPA, Zomba District observed '[one] can spend all his or her time in agriculture but still be very poor while those who are bold enough to venture out to the outside world can prosper within a very short period of time'.

Young people singled out several factors impeding prosperity in the agricultural sector, which were corroborated by MoAI\&WD officials, including: scarcity of land, limited access to improved farm inputs, lack of viable markets and limited extension support. Land is a big challenge for young people because 'it is only the elders and married people who have land of their own to cultivate and not us the youth as we are considered still part of our families'. ${ }^{3}$ As discussed below, young people are marginalised in access to inputs because they are not targeted by the government-supported input programmes. They argued: 'We are told that we are fit enough to work to obtain improved inputs on our own; moreover most of us are not married and are not supposed to need inputs since we are fed by our families'. ${ }^{4}$ Markets are a problem since most areas are inaccessible and it therefore 'takes time and effort to get the produce to lucrative markets which at the end of the day might not be worth it' ${ }^{5}$ There is also a serious lack of loan opportunities to boost agricultural activities. Young women at Malemia Village, Malosa EPA, Zomba District observed: 'We are constrained in taking agriculture seriously because there are no sources of loans for us the youth to invest in the sector. Even if there were loan opportunities, most of us would still be reluctant to engage in agriculture due to lack of extension support: we haven't had an extension officer in our area now for six years'. ${ }^{6}$

Similar observations were made by Butt et al. (2011) in their study of rural young people's perceptions in the Punjab, Pakistan. They also pointed to lack of continuity in agricultural policies, a politicised environment in agricultural support institutions, isolation of agricultural education, research and extension wings, unfavourable prices, buyers and middlemen, absence of infrastructure for farm exports, deficient management and marketing skills, a large number of small operations and unproductive tenancy systems.

The combination of these factors has given agriculture a bad image among the young people as a primary source of livelihood. Most of the young people describe working in the agricultural sector as 'dirty work and demeaning'. ' There is a widespread perception that '[agriculture] is not rewarding and its benefits are long term'. ${ }^{8}$ Others consider agriculture to be 'simply the basic means of survival'. ${ }^{9}$ For the young people in these areas, therefore, there are three alternatives through which they can realise their dreams of the good life: (1) migrating to urban areas in search of employment; (2) engaging in business; and (3) migrating to South Africa. These are considered the surest means of attaining 'the good life', while agriculture is condemned as laborious, less rewarding, exploitative and requiring a long time to reap rewards. Young men of Ibrahim Village, Katuli EPA, Mangochi District observed: 'If you find a decent house with a TV screen and a mountain bike, it is not because of farming; the owners acquired them through other means, such as working in South Africa and while there sent money to their relatives to help them build houses with burnt bricks, roofed with corrugated iron sheets'. MoAI\&WD officials concur: 'The youth do not see agriculture with all its inherent challenges, particularly its low returns and a very long gestation period as a means of attaining their version of [the] good life'. ${ }^{10}$

It is striking, nevertheless, that the importance of agriculture is widely acknowledged among young people. In all the FGDs, young people 
indicated that agriculture was the mainstay for their respective communities. However, this was qualified by a clear statement that the majority of people are in agriculture not by choice but because they have no alternative. 'Given a choice, we would do other things for a living such as business because agriculture is really demanding and there are many factors working against it'. ${ }^{11}$ They stressed that because of the challenges facing the agricultural sector coupled with the processes of land alienation, 'We end up working for others at very exploitative wages which just locks us into a vicious circle of poverty'. ${ }^{12}$ This contributes to the continuing low maize productivity trap for smallholders in Malawi (Dorward and Chirwa 2011).

There is, however, an interesting counter narrative associated mainly with MoAI\&WD officials. They argue that young people are apparently disinterested in agriculture because of their ignorance about the inherent potential of agriculture to transform their lives. 'The problem is that the youth think of agriculture as the domain of the elderly. ${ }^{\prime 3}$ 'They think, being young and dynamic, they need to get rich fast which they feel is not possible working in the agricultural sector but only through engaging in more lucrative non-farm activities. ${ }^{14}$ The apparent disinterest of the youth in agriculture, they argue, simply reflects 'the lack of understanding on the part of the youth of agriculture as a business'. ${ }^{15}$ They nonetheless acknowledge that MoAI\&WD is partly to blame for failing to expound a positive image of agriculture due to the weak extension system. There is, however, a strong feeling that young people will be pushed back into agriculture as the only feasible livelihood strategy due to the worsening economic situation. This could potentially be an opportunity 'to change the youth's perception of agriculture as a sector without viable possibilities to one where they can realise their dreams of a good life'. ${ }^{16}$

\subsection{Lack of supportive policy infrastructure}

The policy environment in Malawi does not encourage young people's involvement in the agri-food sector. Most MoAI\&WD officials observed that no policy framework has been put in place to support the involvement of the youth or cater for their interests in the sector since the transition to democracy in May 1994. There has been a major policy vacuum following the dismantling of the Malawi Young Pioneer (MYP) movement which provided a platform for young people to learn various trades including farming (Englund 2002). By the time they graduated from the MYP training bases, 'the youth were fully equipped to embark on serious farming'. ${ }^{17}$ Without putting in place an alternative, 'the dismantling of the MYP marked the genesis of pushing the youth to the periphery of agricultural activities'. ${ }^{18}$ The MYP was dismantled amid allegations that besides equipping young people to become self-reliant, it also functioned as a paramilitary agency for the Malawi Congress Party. In this guise, the MYP was used to quell dissent against the former one-party regime.

A critical review of major policy documents since May 1994 is quite revealing. Young people are not treated and targeted as a distinct category needing attention in either the Poverty

Alleviation Programme (1994); Vision 2020 (1998); the Malawi Poverty Reduction Strategy (2001); or the Malawi Growth and Development Strategy (2006). Young people do not even appear in the sections on cross-cutting issues dominated by gender, HIV/AIDS, environment and technology. Similar observations were made by Bennel (2007): young people as a group are not a priority of most governments in low-income countries. He argued that ministries of youth are generally very poorly resourced and are usually subsumed or combined with other government responsibilities, most commonly culture, sports and education. The Economic Commission of Africa made similar observations in its review of the national poverty reduction strategy programmes (PRSPs) across the continent in 2005: in only two of 12 PRSPs were young people singled out as a special group in mainstreaming employment and even here, urban youth were of greater concern than rural youth (Bennel 2007). Similarly at a global level, the 2007 World Development Report on Youth devotes only four paragraphs to how to expand rural opportunities for young people and talks here mainly about rural farm activities. The report overlooks the urban youth entirely (ibid.).

The bias towards the non-agricultural sectors is apparent in almost all Malawi government initiatives that have targeted young people since 1994. These have focused on promoting entrepreneurship among young people without any particular emphasis on agri-business, the 
major ones being the Youth Revolving Fund (MK 70 million in 1996); the Malawi Rural Development Fund (MK 4 billion in 2005); and the Youth Enterprise Development Fund (MK 2 billion in 2009). According to Chinsinga (2002), the major problem with initiatives of this nature is that they are often heavily politicised and the urban youth benefit disproportionately. They are often targeted at 'the supporters of the prevailing governing party with no spillovers to the agri-food sector'. ${ }^{19}$

The absence of a supportive policy infrastructure is exacerbated by the reluctance of young graduates from agriculture colleges to work in rural areas. Therefore, even though a good number of people have qualified as experts in extension, the problem of farmers' limited access to extension services persists (Chinsinga 2007). Graduates from Bunda College and the Natural Resources College are reluctant to work in rural areas because of poor living conditions and many are hesitant to work in the public sector because of low pay. As one official observed: 'Graduates are reluctant to work in rural areas because of poor facilities; they are the "network" generation which cannot imagine living in areas without electricity, where phones cannot work, where internet is inaccessible and roads are in a bad shape'.${ }^{20}$ There is an additional constraint for those coming from the Natural Resources College: '[These graduates] are not particularly keen to work in the public sector because they are keen to recoup the exorbitant fees for their studies and most of them have never lived in rural areas before'. ${ }^{21}$ Following the implementation of structural adjustment programmes, the Natural Resources College was privatised; it stopped functioning as a public institution for agricultural extensionists and started admitting students on a market fee basis, putting pressure on them to recoup their investment as soon as possible (Chinsinga 2007). The fear among MoAI\&WD staff is that if this trend continues, 'Very soon there will be a generation of farmers that will be poorly equipped with agricultural skills, worsening the image of agriculture as a viable livelihood strategy'. ${ }^{22}$

\subsection{Marginalisation of young people in agricultural support programmes}

Young people are marginalised in the implementation of agricultural support programmes in Malawi. This is unsurprising given that almost all overarching development strategies are silent on the role of the youth in the sector. Both MoAI\&WD officials and young people themselves gave the Farm Input Subsidy Programme as a classic example of how young people are marginalised in the agricultural sector.

FISP, as discussed above, provides farmers with access to subsidised inputs through the use of vouchers (Dorward and Chirwa 2011). The criteria for targeting FISP have been a subject of contentious debate. The main criticism has been that the targeting criteria are both vague and fluid, changing from year to year and varying across the same areas within the same year. Most official criteria focus on the elderly, widows, orphans, female-headed households and other vulnerable segments of society. Young people are excluded, yet as one official noted, 'Most of them have either never gone to school or are just school dropouts without a job or any tangible source of capital to embark on meaningful farming, ${ }^{23}$

However, since young people are clearly resource constrained, 'It is difficult to understand why they are not the primary target of the programme'. ${ }^{24}$

Similar sentiments were echoed by young people themselves. They observed: 'We are cut out of FISP; we cannot benefit from FISP in our own right but only as members of our families, except those in child-headed households' ${ }^{25}$ As we have seen, the justification for excluding the youth from FISP is that they are strong enough to take care of themselves. Yet opportunities for earning income to raise the required capital are limited. Young women from Ibrahim Village explained: 'They tell us to go out to look for casual labouring jobs to enable us to procure fertiliser, but the only place we can get such work is from the Greek estates where wages are quite exploitative'. These sentiments illustrate how rural Malawi is hard on the young people. As long as they are in good health, they do not deserve sympathy from communities around them. They should be able to survive (Chinsinga 2004).

Some MoAI\&WD officials pointed to the exclusion of the youth from FISP as a missed opportunity in efforts to boost productivity of the agri-food sector given Malawi's current demographic structure: 'The ageing farming population must be addressed in order to guarantee sustainability in agricultural production and food security in the country'. ${ }^{26}$ According to 
Suriname (n.d.), the production of food in the SADC region (of which Malawi is part) will be seriously undermined in the near future if young farmers do not replace the minority ageing cohort. The exclusion of young people is seen as a missed opportunity because 'the success of the agri-food sector is likely to depend largely on the active engagement of the youth since they comprise the biggest proportion of the population'. ${ }^{27}$ The argument is that in addition to sheer numbers, 'the youth also have high levels of energy and since farming in Malawi is predominantly manual, we cannot rely on an ageing population'. ${ }^{28}$ Bennel (2007) argues that young people should be specifically targeted because they have demonstrated greater propensity and willingness to adopt new ideas and technology which may be key to changing the way agriculture is conceptualised, practised and perceived.

\subsection{Land grabs in the eyes of young people}

Both of the study areas are in districts affected by programmes involving land alienation. In

Mangochi District about 400 hectares of land has been sold to Greek farmers who mainly cultivate maize and tobacco, while in Zomba District smallholder farmers are being asked to consolidate their land for purposes of promoting large-scale irrigated agriculture. In this regard, smallholder farmers are letting their pieces of land to be part of one big piece of land for largescale irrigated agriculture. The justification is that this would not only ensure that they reap the benefits of economies of scale but also that all the crop husbandry practices are done at the same time as a collective. The drive to consolidate landholdings is mainly through rehabilitating and expanding the former government-run irrigation schemes under the auspices of the GBI. In both areas, young people believed: 'We are at the periphery of land transactions processes; we only get to be told about the outcomes' ${ }^{29}$ They observed that land deals are dominated by local chiefs and government officials with some involvement of their parents while they themselves are totally ignored 'but we are the future of this area' $\cdot{ }^{30}$ Overall, young people communicated a sense of powerlessness, alienation and hopelessness about ongoing land transactions, yet agriculture remains the principal livelihood strategy for these areas.

The main concern among young people was that the land deals are taking place at a time when the average landholding per capita is declining mainly due to rapid population growth (estimated at 3 per cent per annum: NSO 2008). The hardest hit are young men who, in accordance with the matrilineal cultural system, have to relocate to their wives' homesteads upon marriage. This means they can only access land for agricultural purposes through their wives. Here they observed: 'The land accessed through marriage is often too small to enable one to engage in productive and viable agriculture'. ${ }^{31}$ The custom of relocation was singled out as the most important factor for the young men's disinterest in agriculture in the area. Young married men are often not keen 'to invest their hard-earned resources in "foreign land" because they can be chased out at any time'. ${ }^{32}$ Several studies confirm that the matrilineal (and matrilocal) system contributes significantly to soil fertility degradation since men are not fully committed to undertake the necessary investments to maintain soil fertility (Cross 2002; Kishindo 2004; Kachika 2009).

There are competing discourses among young people about the land alienation in their areas. For many it is a kind of 'love-hate' relationship. Some young people see land grabs as a necessary evil, given the huge challenges to them taking up agriculture independently: 'The new land owners are creating employment and making it possible for us to access improved seed and fertiliser through contract farming arrangements'. Similarly: 'We are better off with the new land owners since they provide us with seed, fertiliser and some jobs that keep our lives going; the government cannot afford to give us these things, so at present we are better off with them around' ${ }^{33}$ For the young people subscribing to this view, their argument was that acquisition of land by foreigners should be facilitated as long as effective mechanisms are put in place to ensure that they give back to their neighbourhood communities. This is in tune with the premise of the GBI concept paper, in which GBI is justified as creating employment opportunities for the local communities whose land is acquired by investors (GoM 2009). However, the question of type of employment is not addressed at all.

Most of the young people in the study condemned the land grabs as exploitative. They argued that the land which is being offered to investors should have been redistributed to them. Although investors are providing some 
employment opportunities, 'very little attention is given to the nature of employment; some of us have been working for them [investors] for three years and we are simply helping them get richer and richer while we remain trapped in a vicious circle of poverty'. ${ }^{34}$ Young people in Ibrahim Village, Katuli EPA, cited the example of maize contract farming they are engaged in. The estate on which they work is involved in maize seed production for Seed Co. While they sell maize to the estate for MK50/kg, the estate sells to Seed Co at MK200/kg. However this MK50 per kg is not their net income because the estate then deducts the cost of seed and fertiliser, and charges a further MK1.00 per planting station for the technical services and labour provided to them. They therefore argued that 'this is highly exploitative with the estate behaving like a money-lending institution'. ${ }^{35}$ The overall view of the young people who subscribed to this perspective was that the so-called investors are simply using them as tools to generate wealth while they descend deeper into poverty.

\section{Conclusions}

While agriculture remains the principal source of livelihood in Malawi and young people are a dominant constituent in the country's demographic structure, they are not fully engaged in the sector. Young people are very much at the periphery of agricultural processes which is clearly reflected in their conception of a good life. They do not see working in the agricultural sector as a viable means of realising their dreams, which they link instead to employment in urban areas, engagement in nonfarm business enterprises and migration to South Africa to do casual labour.

\section{Notes}

1 According to the 2002 land policy almost half of the estates lie idle. This makes the smallholder sector the major source of food security in the country. It contributes as much as 80 per cent of food production in Malawi while the estate sector meets about 15 per cent and the rest comes from either imports or food aid.

2 FGD with young men at Ibrahim Village, Katuli EPA, Mangochi District and young women, Malemia Village, Malosa EPA, Zomba District.

3 FGD with young men, Katuli Village, Katuli EPA, Mangochi District.

4 FGD with young women, Ibrahim Village, Katuli EPA, Mangochi District.
Both the government's Farm Input Subsidy Programme and Green Belt Initiative have further marginalised the involvement of youth in the agricultural sector. Young people are not FISP beneficiaries although the majority are resource constrained. The way in which young people are treated under FISP is a clear manifestation of the fact that rural Malawi is tough on young people. As long as they are in good health, they are expected to fend for themselves. The implementation of the GBI is further complicating young people's access to land, reducing the majority to casual labourers on estates. The initiative does not inspire confidence that the vexing land question will be dealt with once and for all. The political and bureaucratic elite are not keen on finalising overdue land reforms because they are protecting their own interests.

The current situation with regard to young people is seen by officials and young people alike as a missed opportunity, because they are the future of the agricultural sector and will have to replace the minority ageing farming population. According to Suriname (n.d.), the strengths of the youth in the sector include latent energy, capacity and ability to produce and an excellent source of ideas and innovation. The situation that young people find themselves in is exacerbated by policy that does not support their productive involvement in agriculture. Add to this the fact that increasing numbers of young experts are shunning deployment to rural areas, and it is clear why young people are ill-equipped to deal with the challenges of starting up in farming, even if they have the interest, land and capital to do so.

5 FGD with young men, Chitenjere Village, Malosa EPA, Zomba District.

6 Ibid.

7 Interview with an MoAI\&WD official, Katuli EPA, Mangochi District.

8 Ibid.

9 Interview with an MoAI\&WD official, Malosa EPA, Zomba District.

10 Interview with an MoAI\&WD official, Malosa EPA, Zomba District.

11 FGD with young men, Katuli Village, Katuli EPA, Mangochi District.

12 Ibid.

13 Interview with an MoAI\&WD official, Malosa EPA, Zomba District. 
14 Interview with an MoAI\&WD official, Katuli EPA, Mangochi District.

$15 \mathrm{Ibid}$.

16 Interview with an MoAI\&WD official, Malosa EPA, Zomba District.

17 Interview with an MoAI\&WD official, Katuli EPA, Mangochi District.

18 Ibid.

19 Interview with an MoAI\&WD official, Malosa EPA, Zomba District.

20 Ibid.

21 Interview with an MoAI\&WD official, Katuli EPA, Mangochi District.

22 Ibid.

23 Interview with an MoAI\&WD official, Malosa EPA, Zomba District.

24 Ibid.

25 FGD with young men, Ibrahim Village, Katuli EPA, Mangochi District.

\section{References}

AGRA (2009) Fair Play for African Farmers, Alliance for Green Revolution, www.agra-alliance.org/ content/news/detail/871 (accessed 2 March 2012)

Bennel, P. (2007) Promoting Livelihood Opportunities for Rural Youth: Knowledge and Development, Rome: International Fund for Agricultural Development

Bryman, A. (2001) Social Science Research Methods, Oxford: Oxford University Press

Butt, T.; Hassa, M.; Sahi, S.; Aliq, M.; Jabber, A., Amad, I.; Luqman, M. and Shafique, W. (2011) 'Role of Rural Youth in Agricultural and Rural Development: A Self Perceived Case Study of Okara District, Punjab, Pakistan', Journal of Agriculture Extension and Rural Development 3.2: 23-8

Campbell, J. (2002) 'A Critical Appraisal of Participatory Methods in Development Research', International Journal of Social Science Research Methodology 5.1: 19-23

Chingaipe, H.; Chasukwa, M.; Chinsinga, B. and Chirwa, E. (2011) The Political Economy of Land Alienation: Exploring 'Land Grabs' in the Green Belt Initiative in Malawi, research report for FAC-PLAAS Country Study, Bellville: University of Western Cape, South Africa

Chinsinga, B. (2011) 'The Politics of Land Reforms in Malawi: The Case of Community Based Rural Land Development Programme (CBRLDP)', Journal of International Development 23: 1-14

Chinsinga, B. (2010) Seeds and Subsidies: The Political Economy of Input Programmes in Malawi,
26 Interview with District Agriculture

Development Office (DADO) official, Zomba District.

27 Ibid.

28 Interview withan MoAI\&WD official, Malosa EPA, Zomba District.

29 FGD with young men, Ibrahim Village, Katuli EPA, Zomba District.

30 FGD with young women, Malemia Village, Malosa EPA, Zomba District.

31 FGD with young men, Katuli Village, Katuli EPA, Mangochi District.

32 FGD with young men, Chitenjere Village, Malosa EPA, Zomba District.

33 Ibid.

34 FGD with Youth, Ibrahim Village, Katuli EPA, Mangochi District.

35 Ibid.

Future Agricultures Working Paper 013, Brighton: FAC

Chinsinga, B. (2008) Exploring the Politics of Land Reforms in Malawi: A Case Study of the Community Based Rural Land Development Programme (CBRLDP), IPPG Discussion Paper 20, University of Manchester

Chinsinga, B. (2007) 'Reclaiming Policy Space: Lessons from Malawi's Fertilizer Subsidy Programme', paper presented at the World Development Report Workshop, Institute of Development Studies, 21-24 January

Chinsinga, B. (2004) 'Poverty and Food Security in Malawi: Some Policy Reflections on the Context of Crumbling Support Systems', Canadian Journal of Development Studies XXV.2: $320-41$

Chinsinga, B. (2002) 'Politics of Poverty Alleviation: A Critical Review', in H. Englund (ed.), A Democracy of Chameleons: Politics and Culture in New Malawi, Uppsala: Nordiska Africa Institutet, Elander Golab

Chirwa, E. (2008) Land Tenure, Farm Investments and Food Production in Malawi, IPPG Discussion Paper Series 18, University of Manchester

Chirwa, E. (2004) Access to Land, Growth and Poverty Reduction in Malawi, Zomba: Chancellor College, University of Malawi

Chirwa, E.; Dorward A. and Kydd, J. (2006) 'Future Scenarios for Agriculture in Malawi: Challenges and Dilemmas', paper presented at the Future Agricultures Consortium held at the Institute of Development Studies, University of Sussex, 20-21 March 2006 
Cross, S. (2002) Customary Land Tenure, Taxes and Service Delivery in Rural Malawi: A Review of Institutional Features of Rural Livelihoods, LADDER Working Paper 21, Norwich: University of East Anglia

Dorward, A. and Chirwa, E. (2011) 'The Malawi Agricultural Input Subsidy Programme: 2005/06 to 2008/09', International Journal of Sustainability 9.1: 232-47

Englund, H. (ed.) (2002) A Democracy of Chameleons: Politics and Culture in New Malawi, Uppsala: Nordiska Africa Institutet, Elander Golab

GoM (2009) The Green Belt Initiative: Concept Paper, Lilongwe: Ministry of Agriculture and Food Security, Government of Malawi

GoM (2008) National Youth Policy, Lilongwe: Ministry of Youth, Sports and Culture, Government of Malawi

Holden, S. and Tostensen, A. (2011) Appraisal of the Malawi Medium Term for Farm Inputs Subsidy Programme (FISP-MTP) (2011-2016), Lilongwe: Norwegian Embassy

Kachika, T. (2009) Women's Land Rights in Southern Africa: Consolidated Baseline Findings from Malawi, Mozambique, South Africa, Zambia and Zimbabwe, Lilongwe: ActionAid International

Kanyongolo, E. (2005) 'Land Occupations in Malawi: Challenging the Neoliberal Order', in
S. Moyo and P. Yeros (eds), Reclaiming the Land: The Resurgence of Rural Movements in Africa, Asia and Latin America, London and New York: Zed Books

Kishindo, P. (2004) 'Customary Land Tenure and the New Land Policy in Malawi', Journal of Contemporary African Studies 22.2: 213-25

Munthali, T. (2010) Effective Job Creation Strategies for Developing Economies with Bulging Youth Populations, Discussion Paper for the World Bank/IMF Annual Meetings, Washington DC

NSO (2008) The 2008 Population and Housing Census: Preliminary Report, Zomba, Malawi: National Statistical Office

Peters, P. and Kambewa, D. (2007) 'Whose Security? Deepening Social Conflict over Customary Land on the Shadow of Land Reform in Malawi', Journal of Modern African Studies 45.03: 447-72

Smith, W. (1998) Safety Nets in Malawi: How Much? For How Many? , Lilongwe: World Bank in Malawi

Suriname, V. (n.d.), 'Youth in Agriculture: Challenges and Opportunities' (unpublished)

UNESCO (2009) 'Agriculture: Helping to Improve Economic Stability', Information Magazine 3, National Commission for United Nations Educational, Scientific and Cultural Organization 